\title{
Pierre Bourdieu: a distinção de um legado de práticas e valores culturais
}

por Emiliano Rivello Alves*

BOURDIEU, Pierre. A distinção: crítica social do julgamento. São Paulo: Edusp; Porto Alegre, RS: Zouk, 2007.

A obra mais conhecida e mais prestigiada de Pierre Bourdieu, segundo vários autores, traz em boa parte de sua exposição as preocupações decorrentes de anos de estudos sobre a elaboração de uma teoria geral das classes sociais. A distinção: crítica social do julgamento estruturada em três partes, além de introdução, conclusão e post-scriptum, publicada originalmente em 1979 pela editora Minuit, e só agora traduzida para o português, atende às expectativas dos leitores brasileiros não familiarizados com o idioma original, apresentando ricas contribuições aos mais variados campos das ciências humanas.

Bourdieu constrói seu argumento através de um estilo literário refinado e prolixo, com forte tendência ao elitismo, mas justificável pelas pretensões teóricas e práticas alicerçadas no "ideal” que poderia ser encontrado em Questões de Sociologia: "Romper com os automatismos verbais (...) é romper com a filosofia social inscrita no discurso espontâneo" (1983, p. 30). Quando da publicação na França, foi alvo de críticas contundentes e sagazes dos mais distintos segmentos intelectuais e da mídia por, supostamente, projetar uma forte inclinação reducionista, resultando na primeira polêmica pública

\footnotetext{
* Doutorando em Sociologia pelo Programa de Pós-Graduação (PPG-SOL) da Universidade de Brasília. E-mail: emilianorivello@yahoo.com.br
} 
em torno da obra e da biografia de Bourdieu. Em 1981, Bourdieu passa a ocupar a cadeira de Sociologia no renomado Collège de France pelas grandes realizações no campo das ciências sociais, das quais $A$ distinção é parte considerável de seu reconhecimento.

A distinção é uma denúncia violenta e, ao mesmo tempo, uma inspiração para um modelo de compreensão dos mecanismos sociais e culturais, que retira os fatores econômicos do epicentro das análises da sociedade porque remete as práticas de consumo culturais a uma estrutura relacional.

Bourdieu busca estabelecer desde cedo que as práticas culturais juntamente com as preferências em assuntos como educação, arte, mídia, música, esporte, posições políticas, entre outros, estão ligadas ao nível de instrução, submetidas ao volume global de capital acumulado, aferidas pelos diplomas escolares ou pelo número de anos de estudo e, secundariamente, à herança familiar. Na verdade, tratase de desmistificar afirmações da ordem do senso comum quando se assevera que o gosto sobre determinada matéria não se discute; mais do que isso, o gosto classifica e distingue; aproxima e afasta aqueles que experimentam os bens culturais. Mas, de que maneira as preferências culturais dos agentes são estruturadas? Bourdieu responde a esta questão traçando correlações que se iniciam com a transmissão do capital cultural inculcado na escola e aquele herdado pela família, efetuadas de maneira precoce ou através do aprendizado tardio. Pelas ações de imposições positivas de valores - exercidas pela instituição escolar, objetivadas pelo diploma, lembre-se, nas Grandes Écoles -, garantem aos agentes a aptidão para adotar a disposição estética associada a uma origem social. Dito de outro modo, as práticas culturais incentivadas por essas duas instâncias, distinguem aquilo que será reconhecido como gosto legítimo burguês, de classe média ou popular. Assim, é suficientemente importante esclarecer que um gosto da mais alta cultura burguesa 
em matéria de música é mais freqüentemente associado às classes dominantes do que às classes populares e vice-versa.

Nada é tão imperativo quanto o campo de estrutura de relações objetivas que distingue a disposição exigida pelo consumo legítimo das diferentes classes. O esteticamente admirável ou simbolicamente vulgar, por exemplo, em matéria de vestuário ou decoração, é, tão-somente, para os agentes, o socialmente construído pelos capitais acumulados em uma história relativamente autônoma que aprenderam a reconhecer os signos do admirável ou de uma "pseudo-arte", por meio da lógica do campo de poder. Afirmase a dependência da disposição estética em relação às condições materiais de existência, legada pelo passado ou transmitida no presente, através das condições econômicas e sociais do exercício pedagógico da instituição escolar ou da família.

O gosto ou as preferências manifestadas através das práticas de consumo é, então, o produto dos condicionamentos associados a uma classe ou fração de classe. Tais preferências têm o poder de unir todos aqueles que são o produto de condições objetivas parecidas, distinguindo-os todavia de todos aqueles que, estando fora do campo socialmente instituído das semelhanças, propagam diferenças inevitáveis. O gosto, dirá Bourdieu, é a aversão, é a intolerância às preferências dos outros.

A família e a escola tomadas como mercados simbólicos, funcionam como espaços instituidores de competências necessárias aos agentes para atuarem nos diferentes campos. Desse modo, aquela classe ou fração de classe detentora de um elevado capital escolar - portanto, herdeira de um elevado capital cultural -, opõe-se a todas as classes sociais desprovidas desses capitais, pois os gostos são constituídos por capitais metaforicamente dissonantes.

É percebida desta forma que a reprodução moral, ou seja, a transmissão dos valores, virtudes e competências, maneira de ver o 
mundo simbólico, serve, invariavelmente, de fundamento à filiação legítima de habitus distintos e desiguais, fortalecendo e intensificando a hierarquia do culturalmente aceito ou execrável; do autêntico ou do inautêntico exemplificados tais como no cardápio, na decoração do apartamento, na compra de um carro ou mesmo na escolha de um amigo - porque o habitus encontra-se no princípio das afinidades imediatas que coordenam os encontros e as aquisições sociais.

Bourdieu tem o mérito de desvelar de maneira voraz, destarte, que a igualdade de oportunidades e a importância do sistema escolar - ideologicamente incentivadas pelo regime republicano - não garantem, necessariamente, igualdade social a todos.

A posição socialmente ocupada pelos agentes detentores de um poder específico em um campo particular de existência depende, antes de qualquer coisa, dos capitais objetivados nas práticas distinguidos em três dimensões "clássicas": o econômico, o cultural e o social. É a forma assumida pelos capitais objetivados em uma relação e incorporados (habitus) que determinam as classes sociais e, conseqüentemente, constituem as práticas que classificam as distinções.

O habitus é, com efeito, responsável pelas práticas objetivamente classificáveis, sem, contudo, deixar de ser um sistema de classificação. O mundo social, por seu intermédio, é representado nos espaços ou nas posições ocupadas pelos agentes e é ele que estrutura os estilos de vida do campo simbólico. No habitus encontrase inserida toda a estrutura do sistema de condições ou disposições possíveis, fundamentando as estruturas das diferenças. O habitus é o que faz um agente ser detentor de um gosto, porque as preferências estão associadas às condições objetivas de existência.

Os agentes apreendem os objetos ofertados simbolicamente através dos esquemas de percepção e de apreciação de seus habitus. Por isso, é de suma importância deixar claro que cada agente 
confere sentidos e significados distintos a suas práticas. Praticar a mesma atividade física ou consumir os mesmos estilos de filmes não denota, jamais, que o habitus seja gerador de tendências irredutíveis. Bourdieu se defende de uma possível visão determinista contida em sua obra, afirmando que as práticas das diferentes classes ou frações de classes, distribuem-se ao longo de um campo infinito de possibilidades, de tal modo que o número de espaços de preferências será tão grande quanto o universo de possibilidades objetivas.

Em torno dos conceitos de habitus e campo reside uma contribuição importante de Bourdieu ao pensamento sociológico. Tais conceitos têm sido utilizados como instrumentos conceituais que possibilitam pensar as relações entre os condicionamentos sociais exteriores e as subjetividades dos agentes. Eles adquirem um alcance universal na apreensão de certa homogeneidade nas disposições ou nos gostos em matérias que podem ir, por exemplo, da música sertaneja aos hábitos alimentares, das cirurgias estéticas ao comportamento político, das preferências religiosas aos conflitos urbanos juvenis, pois procedem ao reconhecimento dos processos históricos que demarcam a gênese e ampliação das práticas culturais na modernidade.

Em uma época marcada por grandes teorias e trabalhos ensaísticos no campo intelectual francês, Bourdieu se destaca pelo emprego da teoria em nome da pesquisa empírica, possibilitando ao leitor iniciado compreender que as incessantes interpretações e revisões das escolhas individuais não são frutos de ordenamentos isolados ou decorrentes do acaso. A distinção põe em evidência que a lógica intrínseca aos gostos e preferências culturais é aquela submetida à lógica interna de cada campo tomado numa relação simbólica.

É notório destacar que as disputas por posições hierarquizam, igualmente, as oportunidades estatutárias das classes em matéria de valores e concepções políticas. Isso leva a crer que mesmo a 
fração da classe popular com maior capital cultural está submissa às normas e valores dominantes. Os agentes menos competentes - pela perspectiva da cultura legítima - estão à mercê dos efeitos da imposição do campo de produção ideológico influente, acarretando tomadas de posições ligadas às representações "legítimas" do mundo social. Falta-lhes capital escolar, diria Bourdieu, mas que é compensado no blefe inconsciente de uma linguagem que disfarça, sobretudo, posições políticas "desencontradas", "ingênuas" ou "ignorantes".

Ao diploma escolar é reservado um elevado poder simbólico transformando a escola em uma das instâncias sine qua non da manutenção da ordem social. A obtenção do diploma, por definição, "fixa" as disposições dominantes. Trata-se de uma delegação simbólica que desapossa e separa os menos competentes em favor dos mais competentes; os menos instruídos, em favor dos mais instruídos.

As distinções críticas das preferências manifestadas pelos agentes - portanto, as formas de classificação e desclassificação de valores e práticas culturais - são aplicadas em todo e qualquer ponto da distribuição e reprodução dos habitus. As experiências incorporadas do mundo social - a doxa - adesão às relações de ordem aceitas como evidentes, definem os limites, as posições e os legados daquilo que será objetivamente pensado nas estruturas das classes sociais.

Devido ao caráter inovador e interdisciplinar, revolucionário e crítico, ousando no esforço da integração da observação etnográfica e da análise estatística, Bourdieu transforma a própria estrutura conceitual da Sociologia da Cultura, porque cria uma teoria dos fatos culturais comparada às grandes realizações teóricas de Marx, Durkheim e Weber. A distinção, assim sendo, desnuda e explica, ao mesmo tempo, os estudos sobre linguagem, grupos sociais, política, educação, arte ou comunicação, pois oferece uma análise do mundo social de maneira coerente e instigante. 